\title{
José Lezama Lima, filósofo de nuestra América
}

\author{
José Lezama Lima, philosopher of our America
}

\author{
Gastón Ortiz Bandes \\ Colegio Universitario Central, Universidad Nacional de Cuyo, Argentina \\ gastonortizbandes@gmail.com \\ Recibido: 20/04/2021. Aceptado: 22/05/2021.
}

\begin{abstract}
Resumen
El ensayo La expresión americana (1957), de José Lezama Lima puede ser entendido como una contribución a la Historia de las Ideas en nuestra América, en la tradición filosófica de José Gaos, Leopoldo Zea y Andrés Roig. Abordamos así la teoría lezamiana de la imagen y el conocimiento analizando su método mito-poético-hermenéutico y su concepto-personaje "el Señor Barroco" (a través de las figuras de Carlos Sigüenza, sor Juana, José Kondori y Aleijadinho), y contrapunteándola, desde una perspectiva decolonial, con algunas propuestas político-filosóficas contemporáneas: Donna Haraway, Josefina Ludmer, Silvia Rivera Cusicanqui y Achille Mbembe.
\end{abstract}

Palabras clave: Lezama Lima; filosofía; barroco

\begin{abstract}
The essay La expresión americana (1957), by José Lezama Lima, can be understood as a contribution to the History of Ideas in Latin America, in the philosophical tradition of José Gaos, Leopoldo Zea and Andrés Roig. We thus approach the Lezamian theory of image and knowledge by analyzing its myth-poetic-hermeneutical method and its conceptcharacter "the Baroque Lord" (through the figures of Carlos Sigüenza, Sor Juana, José Kondori and Aleijadinho), and establishing relationships, from a decolonial perspective, with some contemporary political-philosophical proposals: Donna Haraway, Josefina Ludmer, Silvia Rivera Cusicanqui and Achille Mbembe.
\end{abstract}

Keywords: Lezama Lima; philosophy; Baroque 


\section{I}

A mediados del siglo pasado, dentro de la filosofía latinoameicana (¿o deberíamos decir las ideas?), había un debate entre Francisco Romero y José Gaos.

Urgido por "acortar distancias con Europa", en Filosofía de la persona (1951) o Sobre la filosofía en América (1952), Romero propugnaba la normalización de la "filosofía" respecto del campo cultural de "las ideas" (artísticas, políticas, científicas), mandándonos a una escuela normal eterna o hasta que la disciplina alcanzase por fin autonomía como práctica profesional al margen de la coyuntura: "La naciente filosofía tiene que ir mucho a la escuela todavía [...] porque todas las precocidades -y más la de la inteligencia-son peligrosas, y en los casos menos graves se resuelven en lamentables pérdidas de tiempo" (1951: 153).

En Pensamiento en lengua española (1945) y En torno a la filosofía mexicana (1952), Gaos proponía en cambio releer nuestra tradición sin horizonte de normalización. Contra una filosofía que de tan madura no se reglara discursivamente para su legitimación institucional, otro avatar eurocéntrico del saber contemplativo como grado sumo de la gnosis, Gaos defendía el pensamiento en sentido amplio, las "ideas" más allá de su formato discursivo, en fin, "una nueva idea de la Historia de la Filosofía" (1980: 16).

Por esos mismos años, en 1957 (falta poco para la Revolución), Lezama Lima dicta cinco conferencias en el Centro de Altos Estudios del Instituto Nacional de Cultura de Cuba, que conforman cada capítulo de La expresión americana, un ensayo a caballo (o unicornio) entre historia y mito. Y poesía, narración, crítica, didáctica, dialéctica, alegoría, misa, magia, danza, lección, cocina, performance. Todo un sistema histórico-filosóficopoiético: auténtico, autónomo pero innormalizable, anti-académico, transdiscursivo, des-colonial.

Por la senda abierta de Gaos, contra Romero y su "escolarización", con La expresión... Lezama apostó en grande a la Historia de las Ideas en 
nuestra América, situando en una "visión histórica", toda su genial "teoría latinoamericana del conocimiento y la imaginación” (González, 2014: 12).

\section{II}

La expresión... se divide en cinco capítulos-conferencias. Una apertura, un cierre $y$, en el medio, tres capítulos que podríamos llamar historiográficos:

1. "Mitos y cansancio clásico" tiene función liminar: en términos retóricos, plantea el problema, explica su método, desarrolla (inventa) sus conceptos. Luego discute con ciertas euro-teorías hegemónicas en la primera mitad del siglo XX, sobre mito, historia, cultura y filosofía.

2. "La curiosidad barroca" esgrime una apología del barroco americano, arma en su honor un "banquete literario" (festín intertextual) con manjares extraídos de ayer y hoy, de aquí (Domínguez Camargo, Reyes, Lugones) y allá (Góngora, Lope), y examina las obras -mientras cuenta sus vidas-de Carlos Sigüenza y Góngora, sor Juana Inés de la Cruz, José Kondori y Aleijadinho.

3. "El romanticismo y el hecho americano" escenifica los procesos independentistas nacionales merced a las siluetas biográficas de fray Servando Teresa de Mier, Simón Rodríguez y Francisco de Miranda, outsiders de la Revolución que configuran "un nuevo destino" (Lezama Lima, 1993: 67).

4. "Nacimiento de la expresión criolla" abarca la consolidación de nuestros estados-nación, revisitando la tradición popular -de la sátira quevedesca a Martín Fierro y Guadalupe Posadas-, para afiliarse finalmente a la herencia ético-intelectual de Martí, "cotidiano imaginario de trabajo" (103).

5. "Sumas críticas del americano" es el epílogo. Plantea más disidencias con las eurovanguardias (y sus críticos) para terminar profundizando en dos conceptos (por ahora) finales de su sistema poético: paisaje y "espacio gnóstico". 
En este trabajo analizaremos el "método" del capítulo 1 y un "conceptopersonaje" del 2: "el Señor Barroco"; contrapunteando las imago-ideas poético-filosófico-historiográficas de Lezama con otros conceptos (y debates) del campo -nunca del todo normalizado- de la filosofía (y la teoría) de ayer y hoy, de aquí (Gaos, Roig, Zea, Rivera Cusicanqui, Ludmer, Santos) y allá (Agamben, Haraway, Deleuze-Guattari, Mbembe).

III

Lezama no dice ideas latinoamericanas sino "expresión americana", y refiere a manifestaciones de nuestra subjetividad singular dentro de la cultura mundial, formas sensibles de expresión que -con ecos de teorías del conocimiento antiguo-medievales (Coccia, 2008)- él llama imagos, quizá porque no habitan solo textos escritos sino también cuadros, estatuas, coplas, muebles, platos, modismos, refranes, chistes, todos médiums del conocimiento.

Lezama, mago gnóstico del siglo XX, busca consciente, políticamente una vía de alto conocimiento a través del mundus imaginabilis, oponiéndose radicalmente al cogito cartesiano del euroconquistador varón blanco heterocis capitalista, que desde el siglo XVI sustituyó con su empirismo y cálculo el saber mágico de las analogías cósmicas:

La imaginación, que actualmente es expulsada del mundo del conocimiento como "irreal", era en cambio para la antigüedad el medium por excelencia del conocimiento. En cuanto mediadora entre sentido e intelecto [...] ocupa en la cultura antigua y medieval exactamente el mismo lugar que nuestra cultura le asigna a la experiencia. Lejos de ser algo irreal, el mundus imaginabilis tiene su plena realidad entre el mundus sensibilis y el mundus intelligibilis, e incluso es la condición de su comunicación, es decir, del conocimiento (Agamben, 2006: 25).

En efecto, La expresión... empieza como una clase de análisis morfológico de figuras en arte, comparando dos imágenes de eurocampesinado: "Septiembre", del Libro de horas del duque de Berry (s. XV), de los hermanos Limbourg, y La cosecha (1565), de Pieter Brueghel. 
Primero, sus elementos comunes: gestos, castillo, cercas. Luego, sus diferencias: en la miniatura, los segadores tienen con su señor una dependencia "estrecha y solemne, [...] vigilada por un hechizo". En el óleo del Viejo, en cambio, los agricultores comen y rastrillan un "cantábile de su propia alegría [...] en un tiempo ideal” (Lezama Lima, 1993: 8).

De ambas "visiones históricas" en esa bisagra entre edades (media/moderna) y clases (campesinado/nobleza), arbitrario pero dialéctico, Lezama pasa a contrapuntear otras dos entidades imaginarias, ahora de un mismo personaje: el canciller Rolin según Jan van Eyck (La Madonna, 1435) y Rogier van der Weyden (El donante, 1450). Y ahí es cuando en un pase (o pose) de saber (mágico) retórico, a estas dos imagos, les suma dos más.

El poeta como mago de los remplazos. En el truco de convencer, las metáforas pasan veloces. De una mano a otra, de una palabra a otra el espectáculo nos convence en el momento justo en que perdemos el hilo de la representación. [...] Ahí, gracias a ese eslabón perdido, el poeta impone su verdad y nosotros le creemos (Kamenszain, 2000: 162).

Performance pedagógica de prestidigitación, "una cabalgata tan alucinante como dialéctica": ahora Lezama retoma aquella "insignificante cerquilla" abierta una página atrás, entre el castillo y los feudos del duque de Berry, para dar el siguiente salto de juglar ${ }^{1}$ al fresco de El capitán da Flagiano (1328) de Simone Martini: "como si aquel estelar castillo, envuelto en el nocturno esmalte de sus bandas azules, que vimos en una tarde de Septiembre [...] abriese sus lentas puertas para dar paso a la arrogante confianza del Caballero" (Lezama Lima, 1993: 9).

Aquí surge lo que Lezama llama "contrapunto animista" entre dos imagos distantes, que necesitan un tercer elemento, nexo o médium que, según él, sería aquí la expresión "puerta que se abre", y que remite a un no

1 Para el "juglar hermético" Lezama, podría postularse la figura del trobar clus medieval y sus "señales, flechas, signos, jaculatorias: el arte de lanzar al vacío pequeños dardos verbales" o "revés de la comunicación" donde tiene lugar la "comunidad de trabajo entre la red Lezama y nuestros indescifrados hábitos de lectura" (Libertella, 1993: 62, 64). 
especificado hexagrama del / Ching ${ }^{2}$. Esoterismo juguetón que aconseja, cual fuere ese hexagrama, grabarlo sobre esa "puerta imaginaria" por la que ahora se cuela -cuarta imago- una leyenda de la etnia ecuatoriana Shuar: Tacquea, única mujer poseedora del fuego, lo guardaba celosamente en su casa, siempre vigilando tras la puerta entreabierta que los hombres no se lo robaran,

hasta que llegó el colibrí [...] y logra burlar las astucias de Tacquea [...] pasea las plumas de su cola por las llamas [...] de allí salta y se irisa por los tejados, exclamando: "iAquí tenéis el fuego! Tomadlo pronto y llevadlo todos"... En donde vemos al gracioso colibrí en el rôle de la gigantomaquia prometeica (Lezama Lima, 1993: 9, 23).

Dos láminas del medioevo europeo, un símbolo chino, una leyenda precolombina (cuyo héroe-colibrí empequeñece a su par titán griego hegemónico): toda una extraña didáctica ejemplar, dialécticamente carnavalesca, "polifonía con cuatro momentos de cultura integrándose" (Lezama Lima, 1993: 9) en un método imago-cognitivo dialéctico y mágico.

\section{IV}

Entidades imaginarias naturales (trigal, noche, estrellas) imbricadas con culturales (castillos hechizados, clases sociales, ornamentos) que "actúan como personajes, que participan como metáforas" (Lezama Lima, 1993: 10): operación herme(néu)tica cuyas analogías son la clave de mutación para hacer pasar, por caso, la figura del caballero, de un lienzo a un libro de Horas, mediante un caprichoso, imprevisto, ¿recién inventado? ideograma del / Ching.

Romero estaría escandalizado. Total falta de rigor metodológico en el método, absoluta falta de objetividad en el estudio de su objeto: contundente oposición a la euro-razón moderna que, sin embargo, por

2 ¿Será $43 \mathrm{Ku}$, "Abrirse paso"? Al menos en la versión de Wilhelm ningún hexagrama se llama "puerta que se abre hacia afuera", a no ser que, ya en otra traducción, se refiera al 60, Chien, "La restricción", aunque en la mutación de 9 en la segunda línea: "No salir de la puerta y el patio trae desgracia" (Jacoby de Hoffmann, 2014: 391). 
supuesto, Lezama justifica. ¿Cómo? Primero, recreando una frase de Literatura europea y Edad Media (1948), de Curtius: “Con el tiempo [...] resultará manifiestamente imposible emplear cualquier técnica que no sea la de la 'ficción'" (Lezama Lima, 1993: 12). Y segundo, rescatando dos nociones clásicas de nuestra filosofía: experiencia ("una nueva visión, que es una nueva vivencia") y sujeto:

Lo que ha impulsado esas entidades, ya naturales o imaginarias, es la intervención del sujeto metafórico, que por su fuerza revulsiva, puso todo el lienzo en marcha, pues, en realidad, el sujeto metafórico actúa para producir la metamorfosis hacia la nueva visión (Lezama Lima, 1993: 10).

Aquí Lezama se pone a discutir de igual a igual con la teoría en boga, mientras

se ve su gabinete de lecturas, qué se lee en ese medio cultural cubano -que no difiere del latinoamericano- respecto de las relaciones de la literatura con el mito. Lezama lee lo que entonces se lee. Pero con ello hace otra cosa, lleva el acto de escritura a la realización práctica de ese mito recompuesto (González, 2014: 10).

Desde un principio es imprescindible para Lezama diferenciarse de Spengler y sus "hechos homólogos", contraponiéndoles "análogos culturales". En la entonces muy influyente Decadencia de Occidente (19181922), ¿̇as formas del cuerno del toro y la tiara bizantina, por ejemplo, adquirían valor simbólico en tanto se pretendía cierta morfología universalista y objetiva? En Lezama interviene un tercer elemento esencial, nexo entre las entidades comparadas: "el sujeto metafórico", productor del análogon.

Nuestro ente de análogo cultural presupone la participación, sobre un espacio contrapunteado, del sujeto metafórico. Pudiéramos tal vez decir que ese sujeto metafórico actúa como el factor temporal, que impide que las entidades naturales o culturales imaginarias se queden gelée en su estéril llanura (Lezama Lima, 1993: 11).

Si Spengler hacía corresponder organismos biológicos y culturales en su esquema isomórfico, para Lezama esos "hechos" están congelados, pues les falta "fuerza animista" dada por ese factor temporal (histórico, situado, 
dialéctico) que es el sujeto metafórico. Y si Spengler somete además la Historia planetaria al cuaternario pitagórico (juventud, madurez, esplendor, decadencia), legitimando la translatio imperii y sus aburridos ciclos, Lezama le confronta entonces a esa máquina homológica clásica imperial un "sujeto metafórico" barroco descolonial, que pone en movimiento esos hechos homologados en su eterna repetición, hacia otro espacio-tiempo no pautado a priori por ningún conquistador.

En síntesis, para Lezama, el "sujeto metafórico" deshiela las homologías imperiales de su diferencia y repetición infinitas, volviéndolas analogías anticoloniales, múltiples, fractales, dialécticas, multiversales. De ahí que Lezama rechace también a Eliot, "pesimista en cuanto él cree que la creación fue realizada por los antiguos y que a los contemporáneos solo nos resta un juego de combinatorias" (Lezama Lima, 1993: 13): "Todo tendrá que ser reconstruido, invencionado de nuevo, y los viejos mitos, al reaparecer de nuevo, nos ofrecerán sus conjuros y sus enigmas con un rostro desconocido. La ficción de los mitos son nuevos mitos" (Lezama Lima, 1993: 14).

En América, pues, el contrapunto entre imagos no depende de una correspondencia formal-funcional dentro de un sistema-código jerárquicorelacional, sino de un sujeto deseante-cognoscente a quien, tras situarse en su paisaje, le es posible pues hacer experiencia o "nueva vida", a través de "la metamorfosis de una entidad natural en cultural imaginaria" o nuevo mito y así "captar el asombro, el nuevo unicornio" $(11,28)$.

¿Qué pensará Romero de la sorpresiva, deslumbrante clase que nos está dando Lezama? ¿Peligrosa precocidad o "lamentable pérdida de tiempo"? Seguirá sosteniendo que, si la filosofía se normalizara en América Latina "como función ordinaria de la cultura", crecería "así la comprensión para el esfuerzo serio", en contra "del aprecio hacia la improvisación brillante, hacia cualquier conato de suscitar la sorpresa o el deslumbramiento" (Romero, 1951: 150)?

Veinte años después, un egresado de la escuela anormal de Lezama podría contestarle: 
La exclamación infalible que suscita toda capilla de Churriguera o del Aleijadinho, toda estrofa de Góngora o de Lezama, todo acto barroco, ya pertenezca a la pintura o a la repostería. [...] ¡Cuánto trabajo perdido, cuánto juego y desperdicio, cuánto esfuerzo sin funcionalidad! Es el superyó del homo faber, el ser para-el-trabajo el que aquí se enuncia impugnando el regodeo, la voluptuosidad del oro, el fasto, la desmesura, el placer (Sarduy, 1999: 1402).

\section{V}

Poeta y filósofo, machi y amauta de la Contraconquista, Lezama combate por lo extraordinario la línea histórica del progreso cartesianohegeliano del homo faber, su teleología o evolucionismo eurocéntricos, de los que el marxismo clásico tampoco estuvo exento ${ }^{3}$, aunque podamos igualmente hacerle orbitar cerca de la Filosofía de la Liberación:

el ego cogito cartesiano nunca tuvo una sola cara, en cuanto que la posesión de la ciencia no le era ajena, en absoluto, a la posesión de la naturaleza y, con ella, esos seres a los que [...] bautizó con el nombre de "naturales". Las Cartas de la Conquista de México (1519-1526), de Hernán Cortés constituyen [...] la versión fáctica del Discurso del Método y el modo como, desde la tragedia, nos abrimos a la modernidad. El ego cogito cartesiano tuvo siempre a su lado, para nosotros en particular, el ego conqueror cortesiano. Cartesianismo y cortesianismo se nos dieron a la par (Roig, 2011: 235-236; también Dussel, 1992).

Lezama no es "pérdida de tiempo": hacia 1957 ya nos desafiaba a alcanzar urgente una "visión histórica" reconstruyendo el tenso y asimétrico proceso por el cual nuestras expresiones culturales fueron manifestándose en un "contrapunto o tejido entregado por la imago, por la imagen participando en la historia" (Lezama Lima, 1993: 7). Operación que, urdiéndola con la escuela de Roig, consistiría en recuperar episodios

$3 \mathrm{Si}$ el blanco de ataque de Lezama es asimismo "la causalidad teleológica de la razón histórica encarnada en la filosofía de Hegel", su interpretación del devenir político cubano se construirá también "a contrapelo del gran relato marxista del momento, lectura materialista de la historia como evolución progresiva de la humanidad" (Luján, 2013: 338), lo que lo llevará a sufrir cierta represiva vigilancia de parte de la ortodoxia revolucionaria en la isla. 
de este proceso cuya legitimidad y alcances se rastrean en el curso de la historia de América Latina, principalmente en sus manifestaciones culturales [...]. La constitución de la subjetividad y las formas de identidad [...] se contemplan como el resultado de una construcción histórica en la que se dan respuestas frente a situaciones de desconocimiento o dominación (Ramaglia, 2009: 391).

De ahí que el sujeto metafórico lezamamiano posea semejanza con el concepto de "a priori antropológico", con el cual Roig nombra el acto de un sujeto empírico cuya temporalidad no se funda "ni en el movimiento del concepto, ni en el desplazamiento lógico de una esencia a otra" (Roig, 2009: 13), como ocurriría en Lezama con los conceptos geleés de los métodos imperiales de Spengler o Eliot.

También en Roig la temporalidad (o descongelamiento) sería producida por un sujeto subalterno, colectivo y colonial, que empieza por "querernos a nosotros mismos" y "tener como valioso el conocernos a nosotros mismos", haciendo de la filosofía una práctica a la que por fin se le restituye “su valor de 'saber de vida', más que su pretensión de 'saber científico', y da a la cientificidad de la misma su verdadero alcance" (Roig, 2009: 13, 11 12).

En nuestro campo ampliado de la Historia de las ideas (o imagos), Lezama resuelve técnicamente la cuestión trans-científica de legitimidad del saber humano con la categoría teórica de "ficción", o sea, el acceso del sujeto a una nueva experiencia cognitiva (o "unicornio"), un instrumento de imaginación cognoscente tan válido para el método historiográficocrítico como la morfología estructural o las leyes de la Física: "Una técnica de la ficción tendrá que ser imprescindible cuando la técnica histórica no pueda establecer el dominio de sus precisiones. Una obligación casi de volver a vivir lo que ya no se puede precisar" (Lezama Lima, 1993: 12).

Articulación ensayístico-performática de producción de saber desobediente a la discursividad normalizada-normalizante. Llevando el acto de hablar-escritura a lo mismo que propone, en La expresión..., esa "nueva vivencia" (o experiencia) del sujeto (metafórico) americano mediante esa ficción (teórica) llamada Señor Barroco. 


\section{VI}

Contemporánea de la Teología de la Liberación, la Teoría de la Dependencia, el Boom y el pop, la llegada del barroco Lezama imantó a una cultura mediática sesentista hispanoamericana concurrente con la Revolución Cubana y aquellas rebeldías juveniles, feministas, disidentes, antirracistas, anticoloniales. Recuerda el editor argentino de Paradiso (1967) cómo una gordísima, enrulada, arborescente novela exudante de teología homoerótica y occulta philosophia, fue best-seller:

Nadie podría haber previsto que, a partir de la recomendación entusiasta hecha por Cortázar [...] pero sobre todo del reportaje al autor realizado por Tomás Eloy Martínez para la entonces todopoderosa Primera Plana [...], la primera edición se vendería... en una sola tarde" (Divinsky, 2006: 435).

Por esos mismos años, en el campo específico de la filosofía latinoamericana, surge otro debate, esta vez entre Augusto Salazar Bondy y Leopoldo Zea, trenzados en torno de la cuestión de la autenticidad en nuestra tradición.

¿Existe una filosofía de nuestra América? (1968), preguntaba desde el título de su libro Salazar Bondy y se contestaba: no. Que, original, en nuestra América no existía ninguna "filosofía". Según él, nuestro pensamiento siempre había sido inauténtico, imitando acomplejadamente modelos europeos y transplantándolos acríticamente a estas pobres tierras. Acusaba así a nuestra intelligentzia por su "conciencia enajenada y enajenante" respecto de nuestras propia comunidades (Ramaglia, 2009: 385).

Y sin embargo, aun culpando al subdesarrollo económico y la dependencia política por nuestra inauténtica mímesis, ¿Salazar Bondy no seguía la senda de Romero, sin entender por original sino un tipo discursivo filosófico más "profesional" que auténtico, una mera equivalencia con el concepto europeo de producción de saber?

Al año siguiente Zea le responde en La filosofía latinoamericana como filosofía sin más (1969). Para él, una filosofía original no puede ser ajena a la reflexión sobre la vida colectiva de los propios pueblos, reafirmando en 
principio nuestra propia humanidad como cualquier otra del mundo: ¿o la tradición ensayística de Bello, Bilbao, Rodó, Vasconcelos, Henríquez Ureña, Ugarte, testimoniaron la "peculiar identidad latinoamericana" a través de una filosofía a secas, sin más (Zea, 1998: 312-313)?

En su reivindicación del barroco Lezama marca un momento crucial en esta forma peculiar de hacer filosofía, desnormalizándola, contraconquistándola, pervirtiendo los patrones discursivos del ego cogito-conqueror, pero sin olvidar que "la filosofía es el arte de formar, inventar, de fabricar conceptos", que a su vez "ya lo veremos, necesitan personajes conceptuales que contribuyan a definirlos" (Deleuze-Guattari, 1993: 8). Con ustedes, el señor Barroco.

\section{VII}

Tildado durante siglos de decadente, artificioso y extravagante, el (señor) barroco, "el arte más anti-occidental que dio Occidente", fue relegado

al kitsch en el siglo XVIII (el arte de las masas "ignorantes" que todavía asistían a las comedias de Calderón) y a la censura oficial y académica en el siglo XIX. En un contexto burgués, racionalista y neo-clásico, el barroco es desterrado siempre a las antípodas del "buen gusto" (González Echeverría, citado por Libertella, 1993: 61).

Como premisa, Lezama embiste diferenciando nuestro barroco del europeo, para él un "gótico degenerado" en su "acumulación sin tensión", su "asimetría sin plutonismo" (1993: 33). Por el contrario, en el barroco hispanoamericano

primero, hay una tensión [...]; segundo, un plutonismo, fuego originario que rompe los fragmentos y los unifica; tercero, no es un estilo degenerescente, sino plenario, que en España y en la América española representa adquisiciones de lenguaje, tal vez únicas en el mundo, muebles para la vivienda, formas de vida y de curiosidad, misticismo que se ciñe a nuevos módulos para la plegaria, maneras del saboreo y del tratamiento de los manjares, que exhalan un vivir completo, refinado y misterioso (Lezama Lima, 1993: 34). 
En Theory of the Earth (1788), James Hutton Ilamó plutonismo a la conjetural formación de los estratos geológicos por la acción del "fuego interior" del planeta. Lezama retoma el ya desusado término para generar parentescos teórico-ficcionales ahora entre ciencia y mito, invocando a la vez al "rico" dios Plutos del reino subterráneo, con sus muertos, misterios órficos y tesoros chthulucénicos (Haraway, 2019). Plutonismo aludiría asimismo a un fuego interior compartido por el sujeto (metafórico) y la tierra que habita, "espacio gnóstico" entre humanes y naturaleza pachamámica, chtónica, que tensa asimétricamente los múltiples fragmentos que componen lo Real (incluidos los mil modos-mónadas de percibirlo).

En medio de la "chorretada de ornamentación sin tregua ni paréntesis espacial libre" que exudan las catedrales virreinales de Perú y Bolivia, por ejemplo, Lezama ve allí sin embargo "un esfuerzo por alcanzar una forma unitiva [...], un impulso volcado hacia la forma en busca de la finalidad de su símbolo" (Lezama Lima, 1993: 35). Desde/con/en esa acumulación infinitesimal, este sujeto americano crea así plenas formas de vida, un sumak kawsay nacido al calor tanto del hogar como de la coyuntura política: un estilo u onda para amoblar, leer, rezar, amar, luchar, bailar, morir.

Así, por un lado, los "fragmentos" en Lezama (y el barroco) tienden a una unidad (o símbolo, cifra, aísthesis) que se nos aparecerá como didáctica ético-política, fundante, per-formática, trayéndonos de nuevo a Gaos:

Entre todos estos temas y formas se hace patente una unidad, que viene a ser la característica radical del pensamiento hispano-americano, aquella sobre la que gravita su significación suma [...]: una pedagogía política por la ética, y más aún la estética; una empresa educativa, o más profunda y anchamente, "formativa" -creadora, o "reformadora", de "independencia", "constituyente" (1954: 87-88)

Y por otro lado, algo más de Roig (o Zea), en cuanto nuestra filosofía como "rescate de la cotidianidad": 
la filosofía es una práctica [pero] no toda práctica es necesariamente "utilitaria" en el sentido peyorativo que el valor "útil" muestra en los pensadores que entienden la filosofía dentro de los viejos esquemas del saber contemplativo (Roig, 2009: 11).

Barroco: modo cotidiano de vida cuyo método de conocimiento histórica se llama "ficción": un artificio que depara una "nueva vivencia" (experiencia) a un "sujeto metafórico" o subjetividad barroca, que

mantiene una relación muy especial con las formas. [Su] geometría [...] no es euclidiana; es fractal. Para [ella], las formas son el ejercicio de la libertad [...] El extremismo con el que son vividas las formas por la subjetividad barroca enfatiza la calidad de artefacto retórico de prácticas, discursos y modos de la inteligibilidad. El artificio (artificium) es la fundación de una subjetividad suspendida entre los fragmentos (Santos, 2009: 243-244, 247).

\section{VIII}

El “señor Barroco" será el personaje que Lezama inventa para probar su método historiográfico consistente en este legítimo artificium teórico llamado "ficción":

Monje, en caritativas sutilezas teológicas, indio pobre o rico, maestro en lujosos latines, capitán de ocios métricos, estanciero con quejumbre rítmica [...] comienzan a tejer [...] un tipo, una catadura de americano en su plomada, en su gravedad y destino. El primer americano que va surgiendo dominador de sus caudales es nuestro señor barroco [...] auténtico primer instalado en lo nuestro, en su granja, canonjía o casa de buen regalo [...] aparece cuando ya se han alejado el tumulto de la conquista y la parcelación del paisaje del colonizador [...] se construye en el sueño de la propia pertenencia, el lenguaje al disfrutarlo se trenza y multiplica; el saboreo de su vivir se le agolpa y fervoriza (Lezama Lima, 1993: 34, 35).

"El señor barroco", cada habitante tipo tras el shock de la conquista, una reflexión individual-colectiva sobre la "pertenencia" colonial. Parodiando a Werner Weisbach y su Barroco, arte de la Contrarreforma (1921), Lezama nos enseñorea un barroco personal y transmutativo como "arte de la contraconquista". Del siglo XVII al XVIII este personaje conceptual va a pasar por distintas etapas y cuerpos, nombres, géneros, 
clases, etnias, en su plutonismo chthulucénico, y va a luchar contra el ego cogito-conqueror mediante múltiples "tretas del débil" (Ludmer, 2021).

Un largo aprendizaje: de aquella construcción de pertenencia de quien ya se instaló "con fruición y estilo normal de vida y muerte" (Lezama Lima, 1993: 34), hasta un segundo momento, entrado el siglo XVII cuando crece la tensión (asimétrica) fragmentos-unidad: Sigüenza, sor Juana, Kondori y Aleijadinho, cuatro identidades por las que transmigrará el señor Barroco, hasta el umbral independentista romántico (cap. 3).

Si la razón capitalista cartesiana logró su objetivo de enterrar para siempre -o quemar como a brujas- el saber mágico de las analogías, el euro-barroco "degenerescente" será el síntoma de esa violenta transición entre dos organizaciones históricas del poder/saber imperial o descentramiento de la episteme renacentista. Pero a nuestro barroco Lezama le da otra vuelta dialéctica de tuerca como formas de lucha contra saqueo, genocidio, sometimiento y coloniaje.

Por eso ya en 1967, en su reseña de Paradiso, un vocero local de la razón capitalista actual desterraba la vía imaginaria de Lezama del mundo del conocimiento "serio" (Romero), suponiéndola "irreal" (Agamben), inscribiéndola directamente en la escuela para-normal:

Nada más difícil que tratar de explicar [...] en qué consiste este sistema poético del mundo en el que Lezama Lima ha comenzado por excluir todo elemento racional y que aparece monopolizado por la metáfora y la imagen, a las que él confiere funciones poco menos que sobrenaturales (Vargas Llosa, 1970: 169-170).

Lezama no excluye ninguna "racionalidad": abre una zona de contacto (taypi) donde, para horror del neoliberalismo, conviven sin monopolio las cosmovisiones mágico-chamánicas de Abya-Yala, Tawantinsuyu, Pindorama, Anahuác y -tras el shock de la esclavitud-África, junto a las búsquedas fáustico-modernas que, chorreando barro y sangre como el Capital, desembocarán en la nueva ciencia y las Luces, censuradas en las colonias de ultramar por la escolástica inquisitorial, claro. 
De esas confluencias, nace una "figura extraordinariamente simpática, de indetenible curiosidad [...] manirroto inveterado, de sotana enamorada": Carlos Sigüenza y Góngora (1645-1700), "señor barroco arquetípico". Ya los títulos de sus libros, Manifiesto filosófico contra los cometas, Libra astronómica, Belerofonte matemático contra la Quimera astrológica, expresan una alianza tipo cyborg entre la imago mundi precopernicana y el espíritu moderno de la ciencia... ficción.

¿Por qué Lezama le da a Sigüenza, "amistoso de la llustración", estatuto de Contraconquista? Pues su curiosidad barroca quebraría el nexo entre poder y saber imperial: en su "afán de conocimiento físico, de las leyes de la naturaleza [...] en ocasiones, apoyándose en el cientificismo cartesiano", iría sin embargo, al contrario del doctor Fausto, "más allá de la naturaleza como tentación para dominarla" (Lezama Lima, 1993: 36-37).

[...] alianzas multiespecies, por encima de las divisiones asesinas de naturaleza, cultura y tecnologia y de organismo, lenguaje y máquina [...] sabiduría situada, mortal y germinal [...] importa qué conceptos pensamos para pensar con ellos otros conceptos (Haraway, 2019: 181).

El contrapunto animista entre planos disciplinarios normalizadamente escindidos, ficciones teóricas y personajes conceptuales en un "com-post" para "sembrar mundos", rescatar historias "compañeras", alianzas transgenéricas, multiespecie:

La historia de la filosofía tiene que pasar obligatoriamente por el estudio de estos personajes, de sus mutaciones en fusión de sus planos, de su variedad en función de sus conceptos. Y la filosofía no cesa de hacer vivir a personajes conceptuales, de darles vida (Deleuze-Guattari, 1993: 64).

\section{IX}

Segunda escena: aquel "afán de conocimiento universal, científico, que acerca a la llustración" al señor barroco Sigüenza, va a representar "una lucha invisiblemente heroica" (Lezama Lima, 1993: 36, 45) cuando este personaje-concepto transmigre de género y se haga monja, devenga Señora. 
En su celda madre Juana (1648-1695) tiene "quinientos polémicos volúmenes", autómatas, probetas, cámaras de eco, telescopios, sumado al conjetural "aprovechamiento que hace para Primero Sueño, de la quinta parte del Discurso del método" (prohibido). ¿Quejas por inautenticidad y enajenación? ¿Mímesis acrítica de modelos europeos? Hojeemos "ese papelillo que Ilaman El Sueño", al que Octavio Paz le adjudicó "un sitio único en la historia de la poesía moderna" en tanto "ruptura radical con el pensamiento europeo de su tiempo" (Paz, 2009: 482, 498).

Hacia 1685, Primero Sueño, "primera vez que en el idioma, una figura americana ocupa un lugar de primacía" (Lezama Lima, 1993: 45), narra la malograda ascensión del alma cognoscente a las esferas supralunares del saber Absoluto. Tras su imaginario escolástico-gongorista y su egiptomanía filtrada por Athanassius Kircher, Lezama y Paz coinciden: el poema excede su alegorismo sobre la potencia individual del conocimiento vislumbrando el empirismo diocechesco y la asunción ética de la subjetividad moderna, "confrontación del espíritu humano y el cosmos" (Paz, 2009: 499).

El Sueño (como la Carta a sor Filotea) exige deconstruir la lectura filosófica del poema atendiendo a la treta retórica (o pase mágico). La "polémica erudita" en sor Juana tiene formato de carta o poema porque eran los únicos géneros discursivos posibles para que una sujeta marginada por el sistema sexo-género colonial tratase la espinosa cuestión del saber/poder en la Nueva España vigilada por el Santo Oficio.

La treta (otra típica táctica del débil) consiste en que, desde el lugar asignado y aceptado, se cambia no sólo el sentido de ese lugar sino el sentido mismo de lo que se instaura en él. Como si una madre o ama de cada dijera: acepto mi lugar pero hago política y ciencia en tanto madre o ama de casa [...] Ante la pregunta de por qué no ha habido mujeres filósofas puede responderse entonces que no han hecho filosofía desde el espacio delimitado por la filosofía clásica sino desde otras zonas, y si se lee o se escucha su discurso como discurso filosófico, puede operarse una transformación de la reflexión. Lo mismo ocurre con la práctica científica o política (Ludmer, 2021: 197-198).

Lezama incluso plantea que la grandeza filosófica del Sueño radica menos en sus "cautelas distributivas, graduaciones del ser, para recibir el 
conocimiento", que en su praxis cotidiana sobre lo real (incluido lo onírico), lo que en América parece ya venir apareciéndosenos como condición apriorística de nuestro pensamiento, o mejor sabiduría situada (de madre o ama de casa que no negocia sus dominios):

no se trata de buscar otra realidad, otra mágica causalidad, sino con visible reminiscencia cartesiana, el Sueño aparece como forma de dominio por la superconciencia. Hay una sabiduría, parece desprenderse del poema, en el sueño, pero trabajada sobre la materia de la inmediata realidad (Lezama Lima, 1993: 46).

\section{$\mathbf{x}$}

El "arte de la contraconquista" interpela desde su realidad al ego cogitoconqueror pero asimilándolos, poniéndolos a trabajar de otra forma menos mortal o invasiva. No excluye (no puede) la euro-modernidad capitalística ni su racionalidad patriarcal-racista, pero las subsume en una historicidad no hegeliana, un sueño super-consciente sin "post ni pre", aunque sí trans", porque "no es lineal ni teleológica [...] se mueve en ciclos y espirales, que marca un rumbo sin dejar de retornar al mismo punto" (Rivera, 2010: 54).

Porque hay una modernidad colonial, el reverso oculto, marginado, reprimido, exterminado de la cultura oficial: mujer, indio, afro; cuyo "pasado-futuro están contenidos en el presente" (Rivera, 2010: 55). Por eso Lezama hace transmigrar por tercera vez al "señor barroco" para confirmarle a Romero, Salazar Bondi y compañía, cuán posible es desde estas tierras "acercarnos a las manifestaciones de cualquier estilo sin acomplejarnos" (Lezama Lima, 1993: 54).

En efecto, al casi ignoto arquitecto autodidacta José "el Indio" Kondori, autor de la fachada de San Lorenzo de Potosí circa 1728, Lezama le atribuye

4 Justamente, para nuestra América respecto de la "Historia Universal" eurocéntrica, Dussel (2001) habla de trans-modernidad y Susana Cella, por su parte, propone abordar la escritura de Lezama desde una "lógica de los -trans" o "descentramiento de oposiciones [...] en los sentidos de 'a través' o 'por' que sugiere el significado del prefijo" (2003: 238). 
“la gran hazaña”. Huérfano oriundo quizá del bajo Chaco tropical, primero en lograr

insertar los símbolos incaicos de sol y luna [junto a] grandes ángeles cuyos rostros de indios reflejan la desolación de la explotación minera [...] Había estudiado con delicadeza y alucinada continuidad las plantas, los animales, los instrumentos metálicos de su raza, y estaba convencido de que podían formar parte del cortejo de los símbolos barrocos en el templo. [...] Fue el primero que, en los dominios de la forma, se ganó la igualdad con el tratamiento de un estilo por los europeos (Lezama Lima, 1993: 53).

Kondori estaba convencido de que los símbolos de su propia cultura sometida al extractivismo podían formar parte con orgullo del espacio semiótico del Otro. ¿Dónde yacería ese complejo de inferioridad latinoamericano del que hablan algunes normalizadores? ¿O sería mejor llamarle "complejo de superioridad de los intelectuales de clase media respecto de sus pares indígenas" (Rivera, 2010: 67)?

Lezama rescata el gesto invaluable de Kondori de reconocerse valioso para sí mismo, ubicándose en igualdad de condiciones dentro del código iconográfico jesuita, yuxtaponiendo la semiluna aymara y el charango a la viña corintia y la viola de gamba, y denunciando la explotación colonialista desde un yo que se hace nosotres, otra condición sine qua non del a priori antropológico:

la filosofía, cuyo comienzo sólo es posible desde un autorreconocimiento de un sujeto como valioso para sí mismo, necesita [...], de un "pueblo", por donde el sujeto no es ni puede ser nunca un ser singular, sino un plural, no un "yo", sino un "nosotros", que se juega por eso mismo dentro del marco de las contradicciones sociales, en relación con las que se estructura el mundo de códigos y subcódigos (Roig, 2009: 15)5.

Al rescatar a Kondori, Lezama adviene pues como precursor de la "Sociología de la Imagen" de Silvia Rivera Cusicanqui y sus estudios crítico-

5 En su "historia latinoamericana del yo", Ariel Schettini halla en el poema de Lezama, "Llamado del deseoso" (1945), el pasaje inaugural de nuestra primera persona lírica al plural: "El yo [...] que construía su sentimentalidad, su conciencia, su lugar frente a la naturaleza y la cultura, en este poema se transforma en 'nosotros' (de la comunidad y de la poesía política) en América Latina" (2009: 217). 
performáticos de nuestras culturas no alfabetizadas con sus propias trayectorias viso-orales al margen de la letra oficial, para reactualizar "muchos aspectos no conscientes del mundo social", ya que en el colonialismo "las palabras no designan, sino encubren" (Rivera, 2010: 19).

La historia política cultural americana en su dimensión de expresividad, aún con más razones que en el mundo occidental, hay que apreciarla como una totalidad. En el americano que quiera adquirir un sentido morfológico de una integración, tiene que partir de ese punto en que aún es viviente la cultura incaica (Lezama Lima, 1993: 76).

Kondori es a Lezama lo que Guamán Poma a Rivera Cusicanqui, dos búsquedas, entre las marañas de letra imperial, de imágenes producidas por autores indígenas, tras la filosofía del mundo andino que posibilitó el Tawantinsuyo, la pregunta por el Ser-en-el-Tiempo o Aka Pacha, tiempoespacio del aquí/ahora. En Ch'ixinakax utxiwa (2010), Cusicanqui descifra los dibujos de la Nueva Crónica y Buen gobierno que hacia 1615 el amauta (artista-poeta-historiador-filósofo) quechua Guamán de Ayala quiso enviarle a Felipe III explicándole su versión de la Conquista y, de paso, cómo debían gobernarse estas tierras.

\section{$\mathbf{X I}$}

Guamán y Kondori, autorizándose ante el rey o la Compañía de Jesús de participar a una misma altura con la propia expresión: he ahí la subjetividad barroca de nuestra "modernidad indígena", "interpelación de las voces [...] relegadas desde un discurso filosófico tradicional" (Fornet-Betancourt: 396), que va a completarse ahora en la última transmigración del Señor Barroco (México-Bolivia-Brasil):

Así como el indio Kondori representa la rebelión incaica [...], en que todos los elementos de su raza y de su cultura tienen que ser admitidos, ya en el Aleijndinho su triunfo es incontestable, pues puede oponerse a los modales estilísticos de su época, imponiéndoles los suyos [...]. Aleijadinho representa la culminación del barroco americano, la unión [...] grandiosa de lo hispánico con las culturas africanas (Lezama Lima, 1993: 54, 55). 
Nacido de esclava en Minas Gerais, la leyenda hace al arquitecto y escultor António Francisco Lisboa, el Aleijadinho (1730-1814), trabajar de noche, tapado a causa de una misteriosa enfermedad, "su gran lepra, que está también en la raíz proliferante de su arte, riza y multiplica", por las iglesias de Ouro Preto, santos con peluca y ropa, profetas de piedra azul tamaño natural y pilastras de "hojas espiraloides que ascienden en ángeles gordezuelos" (Lezama Lima, 1993: 56, 55).

Burlando la "distribución colonial de la mirada" -quién puede o no ver, quién debe volverse invisible (Mbembe, 2016: 185)-, el Aleijadinho de Lezama generaría aquí otro posible parentesco con las teorías anticoloniales de Achille Mbembe para una contribución a "la crítica de la razón negra" en nuestra América y el Caribe, mostrando la potencia política del cuerpo-fetiche-ornamento-cadáver barroco:

[...] sabe bailar con las sombras y tejer relaciones estrechas entre su propia fuerza vital y otras cadenas de fuerza siempre situadas [...] más allá de la superficie de lo visible. [...] Todo poder lo es por su capacidad de metamorfosis [...] de convertirse en otro, de multiplicarse y mantenerse en un movimiento constante [...] saber dar y recibir formas. Pero es también saber desprenderse de formas dadas, [...] abrazar formas de vida inéditas (Mbembe, 2016: 214).

Y así, el señor barroco, que de intelectual heterodoxo (Sigüenza) transmutó de género-sexo (sor Juana) y después de etnia y cultura (Kondori), llega a través de las formas y las metamorfosis con Aleijadinho a una "síntesis" de la imago-expresión-idea-potencia americana, que significa nuestra madurez o potencia histórica para rebelarnos contra los regímenes ibéricos:

[...] el señor barroco americano, a quien hemos llamado auténtico primer instalado en lo nuestro, participa, vigila y cuida las dos grandes síntesis que están en la raíz [...], la hispanoincaica y la hispanonegroide [...] imponente síntesis del Aleijadinho, y en él consideramos lo lusitano formando parte de lo hispánico (Lezama Lima, 1993: 56).

Obvio que estas síntesis entre lo indio, negro, español y portugués, ni mucho menos refleja una situación socio-política igualitaria: "no es posible 
afirmar que esta definición sea la más justa en materia histórica" (Gonzalez, 2014: 18). Por ello, en 1957, Lezama, irónico, se inventa un dicho contra cierto preciso slogan de gobernanza moderno: "Brasil progresa de noche, mientras duermen los brasileños". ¿No está en su treta de trobar clus mago, mientras reconecta con sor Juana y la tensión entre vigilia y sueño, imago y acto, haciendo de la furtiva forma de trabajo del Aleijadinho todo un misterio-praxis a contrapelo del Orden y Progreso?

Si las ideas modernas de libertad, igualdad y democracia son "históricamente inseparables de la realidad de la esclavitud" (Mbembe, 2016: 141), racismo, misoginia e intolerancia colonialistas, nuestra tradición enseña a cada sujeto (metafórico) cognoscente, que cuando se da energía (plutonismo) y movimiento (tensión asimétrica) a formas y conceptos, suele abrírsele una puerta en cada coyuntura (o "visión histórica") si se autoriza barrocamente, queriéndose y valorándose en su colectivo, contra toda normalización imperial-étnico-genérico-intelectual, para fraguar ideas-imagos como "chispas de la rebelión" (Lezama Lima, 1993: 56).

\section{Referencias}

Agamben, Giorgio (2007). Infancia e historia. Buenos Aires: Adriana Hidalgo.

Cella, Susana (2003). El saber poético. Buenos Aires: Nueva Generación.

Coccia, Emmanuele (2008). Filosofía de la imaginación. Buenos Aires: Adriana Hidalgo.

Deleuze, Giles - GUATTARI, Félix (1993). ¿Qué es la filosofía? Anagrama. Barcelona.

Divinsky, Daniel (2006). "Breve historia de Ediciones de la Flor. Editar en la Argentina: ¿un oficio insalubre). La Biblioteca, n. 4-5. 428-451. Disponible en: https://www.bn.gov.ar/micrositios/revistas/biblioteca/la-biblioteca-tercera-epoca-1

Dussel, Enrique (1992). 1492: El encubrimiento del Otro. La Paz: Plural-UMSA.

Dussel, Enrique (2011). "Transmodernidad e interculturalidad". E. Lander (ed.) La colonialidad del saber. Buenos Aires: CLACSO. 45-72.

Fornet-Betancourt, Raúl (1992). Estudios de filosofía latinoamericana. México: UNAM/CCYDEL.

Gaos, José (1945). "Pensamiento de lengua española". Cuadernos americanos, n. 3. Disponible en: 
http://www.cialc.unam.mx/ca/CuadernosAmericanos.1945.3/CuadernosAmericanos.1945 .3.pdf

Gaos, José (1980). En torno a la filosofía mexicana. México: Alianza.

González, Horacio (2014). "Lezama Lima: la trasmutación de la lengua como mito". Lezama Lima. Ensayos barrocos. Buenos Aires: Colihue. 7-42.

Haraway, Donna (2019). Seguir con el problema. Madrid: Consonni.

Jacoby de Hoffmann, Helena (2014). (2014) I Ching. Santiago de Chile: Cuatro vientos.

Kamenszain, Tamara (2000). Historias de amor. Buenos Aires: Paidós.

Lezama Lima, José (1993). La expresión americana. La Habana: Letras Cubanas.

Libertella, Héctor (1993). Las Sagradas Escrituras. Buenos Aires: Sudamericana.

Ludmer, Josefina (2021). Lo que vendrá. Buenos Aires: Eterna Cadencia.

Luján, María Marta (2013). "José Lezama Lima y la Revolución Cubana". T. Basile y N. Calomarde (eds.) Lezama Lima: Orígenes, revolución y después. Buenos Aires: Corregidor. 335-346

Mbembe, Achille (2016). Crítica de la razón negra. Buenos Aires: Futuro Anterior.

Paz, Octavio (2009). Sor Juana Inés de la Cruz o Las trampas de la fe. México: FCE.

Ramaglia, Dante (2009). "La cuestión de la filosofía latinoamericana”. Enrique Dussel, Carlos Mendieta y Carmen Bohórquez (eds.) El pensamiento filosófico latinoamericano, del Caribe y "latino" (1300-2000). México: CREFAL, Siglo XXI. 377-398.

Rivera Cusicanqui, Silvia (2010). Ch'ixinakax utxiwa. Buenos Aires: Tinta Limón.

Roig, Arturo, (1986). "Interrogaciones sobre el pensamiento filosófico". Leopoldo Zea (coord.) América Latina en sus ideas. México: Siglo XXI. 46-71.

Roig, Arturo (2009). Teoría y crítica del pensamiento latinoamericano. Buenos Aires: Una Ventana.

Roig, Arturo (2011). Rostro y filosofía de nuestra América. Buenos Aires: Una Ventana.

Romero, Francisco (1951). Filosofía de la persona. Buenos Aires: Losada.

Santos, Boaventura de Sousa (2009). Una epistemología del Sur. México: Siglo XXI/CLACSO.

Sarduy, Severo (1999). Obra Completa. Buenos Aires: ALLCA XX, Sudamericana.

Schettini, Ariel (2009). El tesoro de la lengua. Entropía. Buenos Aires.

Vargas Llosa, Mario (1970). "Paradiso: una summa poética, una tentativa imposible". P. Simón (ed.) Recopilación de textos sobre José Lezama Lima. La Habana: Casa de las Américas. 169-176.

Zea, Leopoldo (1998). Filosofar: a lo universal por lo profundo. Bogotá: Fundación Universidad Central. 